\title{
Evaluation of Drug-related Emergency Department Admissions in a Tertiary Care Hospital
}

\author{
Gautam Kumar ${ }^{1}$, Navneet Sharma ${ }^{2}$, Ashish Bhalla ${ }^{3}$, Nusrat Shafiq ${ }^{4}$, CVN Harish $^{5}$, Samir Malhotra ${ }^{6}$
}

\begin{abstract}
Aims: To estimate the incidence, severity, preventability, and cost of medication-related problems. To classify patients admitted with medicationrelated illnesses based on causative factors.

Study design: Single-center, cross-sectional, observational study.

Materials and methods: Patient details were collected within 24 hours of admission into emergency. The causality assessment for adverse drug reaction (ADR) was assessed using the Naranjo scale. The modified Canadian emergency department triage and the acuity scale was used for assessment of severity of the ADR and the likely outcome.

Results: We screened approximately 6,050 admissions; of them, 180 (2.97\%) were related to medication-related problems. About 59 (32.8\%) were classified as definitely preventable, $92(51.1 \%)$ possibly preventable, and remaining $29(16.1 \%)$ were not preventable. A total of $103(57.2 \%)$ were categorized as severe, $76(42.2 \%)$ as moderate, and 1 as mild. Average number of drugs received prior to admission was $1.29( \pm 1.15)$, which increased to $6.93( \pm 2.34)$ at the time of analysis. The median (range) cost of medications was $\$ 11.70$ (\$0.32-253.6) per patient per day. Conclusion: Considering the high number of patients admitted with severe illness at the time of admission and the prohibitive cost of medication, we can reduce the financial burden, morbidity, and mortality with drug-related admissions with proper and timely intervention. Also, the inappropriate use of complementary and alternative medications (CAM) should be controlled in order to reduce the incidence of medication-related problems.

Clinical significance: Nonadherence and ADRs constitute majority of admissions due to medication-related problems.

Keywords: Cross-sectional study, Drug-related admissions, Medication-related problems.

Journal of Postgraduate Medicine, Education and Research (2020): 10.5005/jp-journals-10028-1356
\end{abstract}

\section{INTRODUCTION}

Drugs have been credited with increasing the life span, reducing medical care costs, ${ }^{1}$ nearly eradicating some diseases, and providing other economic, social, and individual benefits. ${ }^{2}$ For the success of the medical therapy, patients' adherence is an essential component.

Currently, nearly 1,500 drugs have been approved by the United States Food and Drug Administration (US FDA), ${ }^{3}$ and addition of newer medications has vastly increased treatment options. On the other hand, this has led to an increased risk of medication-related problems. The guiding principle for prescription of drugs should be achievement of an optimal therapeutic outcome and absence of drug-related problems (DRPs). ${ }^{4,5}$

The medication-related problem or DRP is a general term used to denote all outcomes except success, and therefore includes therapeutic failures. Medication-related problems can be further classified into eight distinct categories: adverse drug reaction (ADR), drug interaction (D/I), improper drug selection, untreated indications, subtherapeutic dose, supratherapeutic dose, drug use without indication, and nonadherence. ${ }^{6-10}$ All these DRPs may lead to drug-related hospital admissions (DRA).

Besides morbidity and mortality, DRPs cause significant economic burden, including indirect costs, such as missed days from work, and/or morbidity such as anxiety due to the ADR episode. Drug related admissions also increase costs due to increased hospitalization, prolongation of hospital stays, and additional clinical investigations. One meta-analysis estimated that the proportion of DRA varies between 2.4 and $6.2 \% .{ }^{11}$ In United States alone, financial burden of about US\$ 528.4 billion in 2016 was attributed to DRAs in studies using probability models. ${ }^{12,13}$
${ }^{1,4-6}$ Department of Pharmacology, Postgraduate Institute of Medical
Education and Research, Chandigarh, India
${ }^{2,3}$ Department of Internal Medicine, Postgraduate Institute of Medical 2,3 Department of Internal Medicine, Postgrad
Education and Research, Chandigarh, India

Corresponding Author: Samir Malhotra, Department of Pharmacology, Postgraduate Institute of Medical Education and Research, Chandigarh, India, Phone: +91 1722755243, e-mail: smal.pgi@gmail.com

How to cite this article: Kumar G, Sharma N, Bhalla A, et al. Evaluation of Drug-related Emergency Department Admissions in a Tertiary Care Hospital. J Postgrad Med Edu Res 2020;54(2):29-33.

Source of support: Nil

Conflict of interest: None

The ADR is a "response which is noxious and unintended, and which occurs at doses normally used in humans for the prophylaxis, diagnosis, or therapy of disease, or for the modification of physiological function.."14 Multiple variable factors such as polypharmacy, age, underlying disease, and class to which therapeutic agents belong to influence the overall incidence of ADRs. ${ }^{15}$ A systematic review on 25 different studies peg the overall incidence of $5.3 \%$ of hospital admissions is due to ADRs. ${ }^{16} \mathrm{~A}$ recent study in northeast India has reported the admissions related to ADRs at $0.22 \% .^{17}$

Rates of adherence are usually given as binary: Adherent and nonadherent in results, but adherence can vary from 0 to $100 \% .^{18}$ Adherence rates are usually higher among patients 
with acute conditions, as compared with those with chronic conditions; persistence among patients with chronic conditions is disappointingly low, dropping most dramatically after the first 6 months of therapy. ${ }^{19}$ More than $\$ 100$ billion of avoidable healthcare costs have been attributed to nonadherence in the United States annually, representing 3-10\% of total U.S. healthcare costs. ${ }^{14}$

While most of the factors evaluated in studies from other countries match with those from India, an additional variable is added in the Indian setting. In our previous studies, we have seen that a considerable proportion of patients use traditional systems of medicine. ${ }^{20,21}$ Complementary and alternative medicine (CAM) is poorly recorded and some patients stop taking modern medicines either on advice of a CAM practitioner or on their own leading to emergency visits or admissions. In one study, 59 of 101 patients used 129 forms of CAM in the month before admission, but only 36 were documented in the medical records. ${ }^{22}$

It is important to study the factors responsible for medicationrelated problems as more than half of them are preventable. ${ }^{23}$ This study was planned to estimate incidence, severity, preventability, and cost associated with medication-related problems in the patients in medical emergency outpatient (EMOPD) and ward (EMW). A secondary aim was to classify patients with medicationrelated problems into categories based on causative factors to identify the most commonly implicated causes.

\section{Materials and Methods}

\section{Study Approval}

The study protocol was approved by the Institutional Ethics Committee. Waiver of an informed consent was obtained from the Ethics Committee as the study only involved collection of data and there was no interference with the patients' management. The confidentiality of information obtained from the patients was ensured.

\section{Study Design, Data Collection, and Assessment}

Demographic data were collected from all patients. Each patient or his/her caregiver was interviewed, preferably within 24 hours of admission for documenting the chief complaint, history of current illness, past medical history including history of allergy, history of noncompliance and reasons for noncompliance, and any ADRs. In our setting, it is not unusual for people to not carry the exact prescription, and the containers or blisters of drugs prescribed and consumed are frequently not available. Medication history included all medication received including prescription, over-the-counter (OTC), and CAM medications. Information regarding other crucial factors such as dose, timing, drug holidays, and switch to alternate prescription or alternative medicine, which may be important in determining clinical outcomes, was taken in more detail.

The frequency of medication intake was recorded to determine adherence to therapy. Simple questions like "Did you take all your medications all the time?" were asked. ${ }^{24}$ Responses were varied, including none of the time, a little of the time, some of the time, a good bit of the time, most of the time, and all the time. Those responses that included either "most of the time" or "all the time" were considered adherent and rest of the responses considered nonadherent.

The visit was considered medication-related if the presenting complaint fell into any one of the eight categories of DRPs. The causality assessment for ADR was thereafter subjected to the Naranjo scale for further assessment. ${ }^{25}$ The modified Canadian emergency department triage and acuity scale (CTAS) was used to help in the assessment of severity of the disease and its likely outcome. $^{26}$

The assessment of patients included the overall condition of the patient including physical appearance, stress level, emotional response, and their concerns about the future course of illness in their own words. ${ }^{27}$ It was followed by basic questions from patients or their attendants regarding presenting complaint, culminating in more targeted questions among the most serious or bothersome complaints. Then their overall prognosis and laboratory tests, if any available, were taken into the account to a get an overall picture of the prognosis to determine the severity of the condition.

\section{Statistics}

For categorical data, frequencies and percentages were used. For continuous data, mean $( \pm S D)$ or median (range) was used. All the analysis was done using Microsoft Excel 2016 or SPSS (version 22).

\section{Results}

The study was conducted in a 1,800-bed tertiary care teaching hospital. During the study period, approximately 6,050 patients were evaluated in the emergency OPD and the emergency ward. Among the admitted patients, 180 cases were found to be drugrelated, of which 97 (54\%) were male and 83 (46\%) were female. Their mean age ( $49.9 \pm 18.5$ years) was similar among both males and females.

The most common medication-related admissions were due to diabetic ketoacidosis $(67,38 \%)$, followed by cerebrovascular accidents (34, 19\%) (Fig. 1). Nonadherence was the most frequent category $(128,71 \%)$, followed by subtherapeutic dose $(21,12 \%)$ (Table 1). The CAM use was a reason for admission in 13 (7.2\%) cases.

Sixteen cases were classified as probable ADRs (Naranjo score 5-8), and three ADRs were attributed to CAM (possible, Naranjo score 4). Five cases were due to drug interaction, and two included breakthrough seizures due to reduced antiepileptic drug levels following chronic alcohol consumption. Two cases of CAM use were related to antidiabetic medication where the patients had CAM as

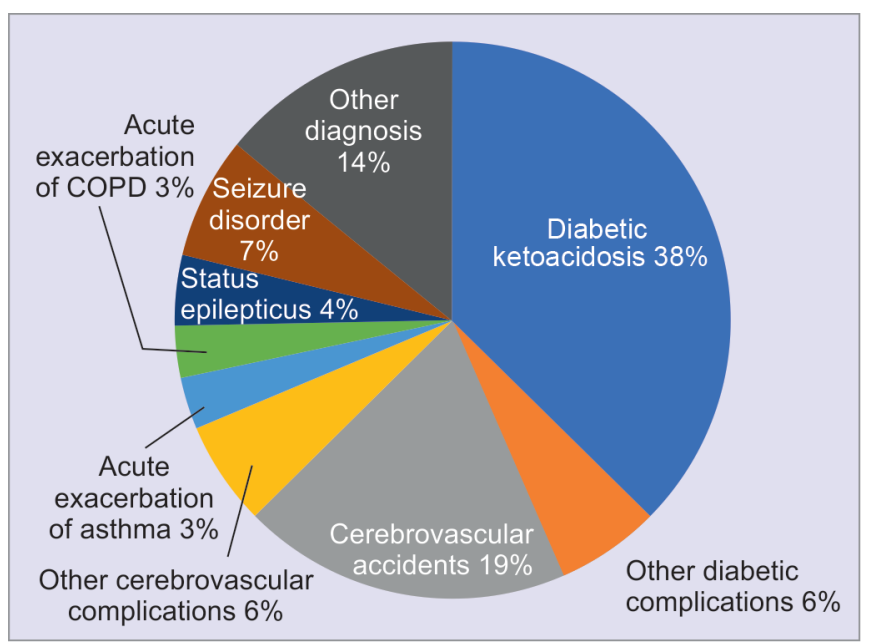

Fig. 1: Diagnosis at admission for the patients admitted due to medication-related problems. Other diabetic complications include diabetic foot, diabetic neuropathy, and hyperosmolar hyperglycemic coma. Other cerebrovascular complications include intracranial hemorrhage, subdural hemorrhage. COPD, acute exacerbation of chronic obstructive pulmonary disease 
Table 1: Number of patients admitted due to medication-related problems under distinct categories

\begin{tabular}{lc}
\hline Indication & Number of cases (\%) \\
\hline ADR & $19(10.5 \%)$ \\
Drug interaction & $5(2.9 \%)$ \\
Untreated indication & $3(1.7 \%)$ \\
Subtherapeutic dose & $21(11.7 \%)$ \\
Supratherapeutic dose & $3(1.7 \%)$ \\
Drug use without indication & $1(0.5 \%)$ \\
Nonadherence & $128(71 \%)$ \\
CAM & 13 \\
Total & 180 \\
${ }^{*}$ CAM cases have been included under different categories individually
\end{tabular}

Table 2: Drugs implicated in causing hospital admission due to suspected nonadherence of drugs $(n=128)$

\begin{tabular}{lc}
\hline Drugs classes & Number of cases (\%) \\
\hline Antihypertensive & $20(15.6 \%)$ \\
Oral hypoglycemic agents (OHA) & $26(20.3 \%)$ \\
Insulin & $25(19.5 \%)$ \\
Insulin + OHA & $5(3.9 \%)$ \\
Antiepileptic & $9(7.0 \%)$ \\
Antitubercular drugs & $2(1.35 \%)$ \\
Thyroid & $7(4.72 \%)$ \\
Antiplatelet & $2(1.35 \%)$ \\
Antiangina & $2(1.35 \%)$ \\
Anticancer & $1(0.7 \%)$ \\
Bronchodilators & $12(8.1 \%)$ \\
Others & $11(7.43 \%)$ \\
CAM & $6(4.7 \%)$ \\
Total & 128 \\
\hline
\end{tabular}

Table 3: Drugs prescription cost per patient per day admitted due to medication-related problems

\begin{tabular}{|c|c|c|c|}
\hline Condition & $\begin{array}{l}\text { Number of } \\
\text { cases }\end{array}$ & Mean (SD) & Median (range) \\
\hline ADR & 19 & $\$ 39.56(\$ 48.88)$ & $\begin{array}{l}\$ 24.61 \$ \\
(\$ 0.32-168.37)\end{array}$ \\
\hline $\begin{array}{l}\text { Drug interaction } \\
(D / I)\end{array}$ & 5 & $\$ 24.54(\$ 14.41)$ & $\begin{array}{l}\$ 23.44 \\
(\$ 8.74-122.78)\end{array}$ \\
\hline $\begin{array}{l}\text { Improper drug } \\
\text { selection }\end{array}$ & 0 & - & - \\
\hline $\begin{array}{l}\text { Untreated } \\
\text { indication }\end{array}$ & 3 & $\$ 10.15(\$ 10.15)$ & $\begin{array}{l}\$ 11.76 \\
(\$ 5.81-12.9)\end{array}$ \\
\hline $\begin{array}{l}\text { Subtherapeutic } \\
\text { dose }\end{array}$ & 21 & $\$ 23.3(\$ 23.3)$ & $\begin{array}{l}\$ 12.24 \\
(\$ 2.57-144.65)\end{array}$ \\
\hline $\begin{array}{l}\text { Supratherapeutic } \\
\text { dose }\end{array}$ & 3 & $\$ 79.78(\$ 89.31)$ & $\begin{array}{l}\$ 53.76 \\
(\$ 6.35-179.22)\end{array}$ \\
\hline $\begin{array}{l}\text { Drug use without } \\
\text { indication }\end{array}$ & 1 & - & - \\
\hline Nonadherence & 128 & $\$ 20.62(\$ 27.54)$ & $\begin{array}{l}\$ 9.58 \\
(\$ 0.77-169.43)\end{array}$ \\
\hline Total & 180 & $\$ 25.03(\$ 36.27)$ & $\begin{array}{l}\$ 11.62 \\
(\$ 0.32-233.22)\end{array}$ \\
\hline
\end{tabular}

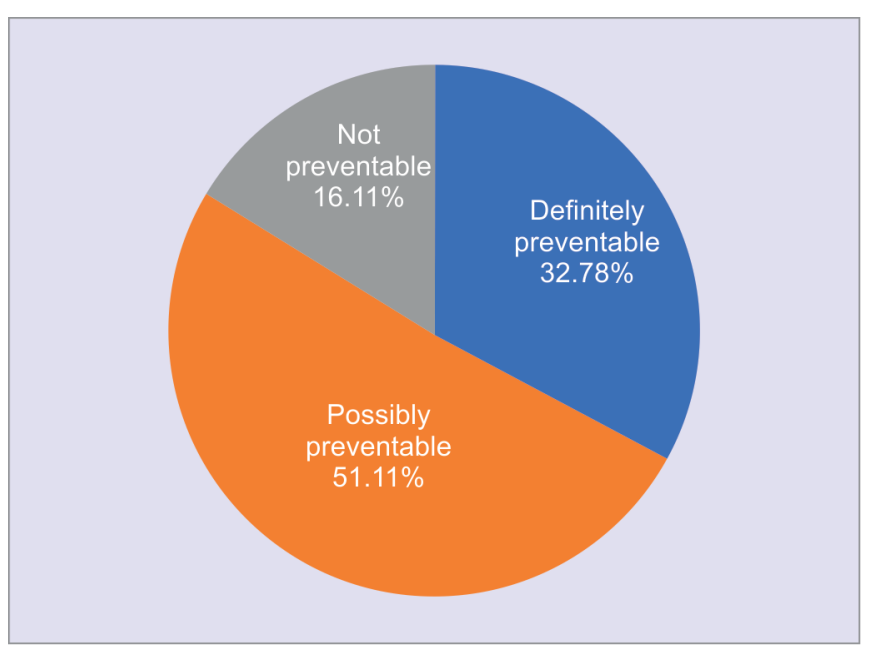

Fig. 2: Preventability of cases for patients admitted due to medicationrelated problems

Table 4: Drugs prescription cost at per patient per day classified into different groups due to medication-related problems

\begin{tabular}{lc}
\hline Range & Cases $(\%)$ \\
\hline$\$ 0.32-3.84$ & $26(14.4 \%)$ \\
$\$ 3.85-7.69$ & $39(21.7 \%)$ \\
$\$ 7.70-15.38$ & $42(23.3 \%)$ \\
$\$ 15.39-23.07$ & $14(7.8 \%)$ \\
$\$ 23.08-30.77$ & $13(7.2 \%)$ \\
$\$ 30.78-38.46$ & $13(7.2 \%)$ \\
$\$ 38.47-46.15$ & $14(7.8 \%)$ \\
$>\$ 46.15$ & $19(10.6 \%)$ \\
Total & $180(100 \%)$ \\
\hline
\end{tabular}

add-on therapy and patients presented with DKA, although the exact reason for interaction could not be ascertained.

Oral hypoglycemic agents (OHAs) (29 cases; $22.6 \%$ ) and insulin (27 cases; $21.1 \%$ ) were the most common drugs implicated in the category of nonadherence (Table 2 ). Six cases (4.7\%) were attributed to patients switching to CAM and stopping modern medication.

A total of $59(33 \%)$ cases were classified as definitely preventable, $92(51 \%)$ were possibly preventable, and the remaining 29 (16\%) were not preventable (Fig. 2). A total of 103 cases (57\%) were categorized as severe, 76 (42\%) moderate, and 1 was mild.

The average number of drugs received prior to admission was $1.29 \pm 1.15$ with 41 (23\%) having history of receiving no therapy at admission. After admission, there was appreciable rise in average number of drugs given per patient to $6.93 \pm 2.34$, with patients receiving 2-14 drugs at admission. The maximum number of patients received eight drugs (34 cases; 19\%) followed by seven drugs (32 cases; 18\%). Antimicrobials (214) contributed to maximum number of drugs followed by antihypertensives and insulin.

The median (range) cost of medication/patient/day was US\$ 11.70 (0.5-233.6) (Table 3). Most patients spent $\$ 7.70-15.38$ on drugs (42 cases; $23 \%$ ) followed by those who spent $\$ 3.85-7.69$ (39 cases; $22 \%$ ) (Table 4). The overhead costs (bed charge, consumables, transportation, loss of wages, cost of stay of patient attendants, any disability or death) were not included in our analysis as the study was not designed to address the issue. 


\section{Discussion}

The study was done in the medical emergency of a multispecialty tertiary care teaching hospital in north India, which is a referral hospital with patients availing the services from the neighboring states and even from far-off places. The Indian setup is different from the West due to the fragmented nature of healthcare system, overlapping government and private health care, and little insurance cover for most Indians. Collective data regarding use of drugs and prescription in India are deficient in many cases reducing the overall efficiency of reporting of the incidence of medicationrelated admissions.

The key findings of this study were that about 3\% of emergency visits were related to medication-related problems, the majority (83\%) of them being definitely or possibly preventable. Expectedly, most of them were severe or moderate. The total number of cases collected were most likely underestimate cases who were admitted to emergency for less than 24 hours or those whose proper diagnosis was not mentioned or working diagnosis was not suggestive at the time of screening were likely to be missed. Nonavailability of proper documentation of previous treatment and patient attendants not well versed with proper history and chronology of treatment could also have contributed to underreporting. We used a nonjudgmental manner of questioning so as to obtain accurate history but cannot rule out patients/ attendants not telling us the complete truth.

Nonadherence to the medication is known to be a major contributor to medication-related admissions. In this study, 128 cases $(71 \%)$ were due to nonadherence, with the majority being chronic disorders (diabetics and hypertensives), which was in line with the other studies. ${ }^{28}$ Our study renews focus on the need for educating patients on the importance of adherence to medication especially for chronic disorders.

Another problem relevant to our setting is that patients do usually carry their prescription or the empty blisters of used medicine. Also, other factors, such as low health literacy, lack of information regarding medication, missing doses, drug holidays, and switch to CAM, may be responsible for overall adverse outcomes.

The study reported 21 cases of the potential subtherapeutic dose, which is a problem that needs special attention and future research as it often arises from lack in coordination between a physician and patient in the long run.

The cost of medication-related problems is quite high, which imposes significant financial burden on the patients. Since our study was cross-sectional, we could not analyze the cost of complications arising from nonadherence, ADRs, or CAM use.

Another important issue highlighted by this study is the inappropriate use of CAM, with patients often stopping their medications after starting CAM. Two things need to be discussed here. First, it is extremely difficult to elicit such history from patients as they either deny use of CAM or deny stopping medication. Second, many CAM practitioners widely advertise their "cures" for not only a variety of chronic diseases (epilepsy, diabetes, rheumatoid arthritis) but also diseases like cancer and HIV. A future study may be planned only to evaluate the incidence of such use, not only in emergency but also among outpatients.

Finally, our study showed that nearly $84 \%$ such conditions are preventable. Considering the high number of patients admitted with severe illness at the time of admission and the prohibitive cost of medication, we can reduce the financial burden, morbidity, and mortality due to drug-related admissions with proper and timely intervention.

The major strengths of the study were evaluation of a large number of cases for evaluation of medication-related visits, careful assessment of cases for causality, preventability, and severity, and focus only on emergency cases, which the study design allowed to capture. The main limitations of the study were that we may have underestimated the number of cases because of lack of proper records the patients had available and the inability of attendants to provide complete information at the time of admission.

While a number of systematic reviews and studies have evaluated medication-related problems in hospitalized patients, a systematic review on patients coming to the emergency with medication-related problems is required.

A controversial issue this study raises is the association of CAM use with nonadherence leading to emergency visits. Such history is exceedingly difficult to elicit and more public education with respect to proper treatment adherence is required. More research in this area, specifically looking at this aspect only, is urgently needed.

\section{Conclusion}

While nonadherence and ADRs are well-recognized cause of drugrelated admissions, as seen in several studies including this, the fact that about $5 \%$ (in most likelihood a gross underestimate) of those admitted were directly or indirectly related to CAM use should raise immediate concerns.

\section{Clinical Significance}

Drug-related admissions accounted for about 3\% of emergency admissions in this study. Nonadherence and ADRs remain wellrecognized causes of DRAs and were responsible for the majority (82\%) of admissions. Approximately $5 \%$ of those admitted were directly or indirectly related to CAM use. This is in most likelihood a gross underestimate.

\section{References}

1. Congressional Budget Office (2012). Offsetting effects of prescription drug use on medicare's spending for medical services. Congressional Budget Office Report. Available at http://www.cbo.gov/sites/default/ files/cbofiles/attachments/43741-MedicalOffsets-11-29-12.pdf. Accessed on June 26, 2017.

2. Manasse HR. Medication use in an imperfect world: drug misadventuring as an issue of public policy, part 1. Am J Health Syst Pharm 1989;46(5):929-944. DOI: 10.1093/ajhp/46.5.929.

3. Kinch MS, Haynesworth A, Kinch SL, et al. An overview of FDAapproved new molecular entities: 1827-2013. Drug Discov Today 2014;19(8):1033-1039. DOI: 10.1016/j.drudis.2014.03.018.

4. Roxburgh A, Degenhardt L. Characteristics of drug-related hospital separations in Australia. Drug Alcohol Depend 2008;92(1-3):149-155. DOI: 10.1016/j.drugalcdep.2007.07.020.

5. Sekhar MS, Mary CA, Anju PG, et al. Study on drug related hospital admissions in a tertiary care hospital in South India. Saudi Pharm J 2011;19(4):273-278. DOI: 10.1016/j.jsps.2011.04.004.

6. Van den Bemt PM, Egberts TC, de Jong-van den Berg LT, et al. Drugrelated problems inhospitalised patients. Drug Saf 2000;22(4):321333. DOI: 10.2165/00002018-200022040-00005.

7. Strand LM, Morley PC, Cipolle RJ, et al. Drug-related problems: their structure and function. DICP 1990;24(11):1093-1097. DOI: $10.1177 / 106002809002401114$.

8. Hepler CD, Strand LM. Opportunities and responsibilities in pharmaceutical care. Am J Hosp Pharm 1990;47(3):533-543. DOI: 10.1093/ajhp/47.3.533. 
9. Nelson KM, Talbert RL. Drug-related hospital admissions. Pharmacotherapy 1996;16(4):701-707.

10. Zed PJ, Black KJ, Fitzpatrick EA, et al. Medication-related emergency department visits in pediatrics: a prospective observational study. Pediatrics 2015;135(3):435-443. DOI: 10.1542/peds.2014-1827.

11. Roughead EE, Gilbert AL, Primrose JG, et al. Drug-related hospital admissions: a review of Australian studies published 1988-1996. Med J Aust 1998;168(8):405-408. DOI: 10.5694/j.1326-5377.1998. tb138996.x.

12. Ernst FR, Grizzle AJ. Drug-related morbidity and mortality: updating the cost-of-illness model. J Am Pharm Assoc 2001;41(2):192-199. DOI: 10.1016/S1086-5802(16)31229-3.

13. Watanabe JH, Mclnnis T, Hirsch JD. Cost of prescription drug related morbidity and mortality. Ann Pharmacother 2018;52(9):829-837. DOI: 10.1177/1060028018765159.

14. IMS Institute for Healthcare Informatics. Avoidable costs in US health care. 2013. Available at: http://www.imshealth.com/deployedfiles/ imshealth/Global/Content/Corporate/IMS\%20Institute/RUOM2013/IHII_Responsible_Use_Medicines_2013.pdf. Accessed June 26, 2017.

15. Lobo MG, Pinheiro SM, Castro JG, et al. Adverse drug reaction monitoring: support for pharmacovigilance at a tertiary care hospital in Northern Brazil. BMC Pharmacol Toxicol 2013;14:1-7. DOI: 10.1186/2050-6511-14-5.

16. Kongkaew C, Noyce PR, Ashcroft DM. Hospital admissions associated with adverse drug reactions: a systematic review of prospective observational studies. Ann Pharmacother 2008;42:1017-1025. DOI: 10.1345/aph.1L037.

17. Laskar JI, Chakravarty P, Dewan B. A study on incidence of adverse drug reactions with commonly prescribed drugs and causality assessment in Silchar Medical College and Hospital. Int J Basic Clin Pharmacol 2017;6(5):1175-1183. DOI: 10.18203/2319-2003. ijbcp20171673.

18. Spilker B. Methods of assessing and improving compliance in clinical trials. In: Cramer JA, Spilker B, ed. Patient compliance in medical practice and clinical trials. New York: Raven Press; 1991. pp. 37-56.
19. Jackevicius CA, Mamdani M, Tu JV. Adherence with statin therapy in elderly patients with and without acute coronary syndromes. JAMA 2002;288(4):462-467. DOI: 10.1001/jama.288.4.462.

20. Malhotra S, Bhatia GS, Pandhi P. Patterns of use of unconventional therapies in the medical outpatient department of a tertiary care hospital in India. J Ethnopharmacol 2001;75(2-3):71-75. DOI: 10.1016/ S0378-8741(00)00380-9.

21. Shafiq N, Gupta M, Kumari S, et al. Prevalence and pattern of use of complementary and alternative medicine (CAM) in hypertensive patients of a tertiary care center in India. Int J Clin Pharmacol Ther 2003;41(7):294-298. DOI: 10.5414/CPP41294.

22. Cockayne NL, Duguid M, Shenfield GM. Health professionals rarely record history of complementary and alternative medicines. Br J ClinPharmacol 2005;59(2):254-258. DOI: 10.1111/j.13652125.2004.02328.x.

23. Zed PJ, Abu-Laban RB, Balen RM, et al. Incidence, severity and preventability of medication-related visits to the emergency department: a prospective study. CMAJ 2008;178(12):1563-1569. DOI: 10.1503/cmaj.071594.

24. Lu M, Safren SA, Skolnik PR, et al. Optimal recall period and response task for self-reported HIV medication adherence. AIDS Behav 2008;12(1):86-94. DOI: 10.1007/s10461-007-9261-4.

25. Naranjo CA, Busto U, Sellers EM, et al. A method for estimating the probability of adverse drug reactions. ClinPharmacolTher 1981;30(2):239-245. DOI: 10.1038/clpt.1981.154.

26. The Canadian Triage and Acuity Scale: Education Manual. Available at:http://caep.ca/sites/caep.ca/files/caep/module_1_slides_v2.5.pdf. Accessed on 16 June 2017.

27. Howard RL, Avery AJ, Howard PD, et al. Investigation into the reasons for preventable drug related admissions to a medical admissions unit: observational study. QualSaf Health Care 2003;12(4):280-285. DOI: $10.1136 /$ qhc.12.4.280.

28. Sabaté E. Adherence to Long-Term Therapies: Evidence for Action. Geneva: World Health Organization; 2003. Accessed from: https:// www.who.int/chp/knowledge/publications/adherence_report/en/. Accessed on: 21.6.2019. 